\title{
PENGARUH SIKAP KONSUMEN TERHADAP MARKETING MIX HOSPITALITY
}

\author{
Kusuma Chandra Kirana \\ STIE Mitra Indonesia Yogyakarta \\ e-mail: kusumack_192@yahoo.com
}

\begin{abstract}
Yogyakarta has been known as the city of tourism for the many culture and heritage in this region. The city of Heritage attached to it, has an impact on people's behavior in the consumption of products or services. A demand for good tourism on the products service has encouraged the growth of industries that promote values. Hospitality, an industry engaged in social services, is growing rapidly in Yogyakarta. The industry deals with hospitality services and management of socio-religious events, such as weddings. Based on the data obtained, people of Yogyakarta are very sensitive to the appropriate product warranties. This study used descriptive statistics of Likert shari'i scale, a modified Likert scale. Data were analyzed using Fishbein formulation. The results of the above studies indicate that the overall consumers'attitude towards hospitality marketing mix in Yogyakarta is positive with the value of Ao: +5.1601 . On the other hand, the score of partial assessments of hospitality marketing mix in Yogyakarta are as follows; product assessment Ao $=+1.047025$, price Ao $=0.58305$, location Ao $=+0.980075$, promotion Ao $=$ $+0.3479$
\end{abstract}

Keywords: attitude, marketing mix, hospitality

\section{PENDAHULUAN}

Yogyakarta, dikenal dengan kota pariwisata, karena penuh dengan budaya dan keindahan alamnya. Keragaman budaya juga ada di Yogyakarta sebagai dampak banyaknya mahasiswa dari berbagai wilayah di Indonesia yang kuliah di kota ini. Citra kota pelajar juga melekat di Yogyakarta. Hal ini, ternyata membawa dampak terhadap perilaku masyarakat dalam konsumsi terhadap suatu produk maupun jasa. Tuntutan terhadap kualitas produk telah mendorong tumbuhnya industri yang mengedepankan nilai-nilai produk yang baik.

Hospitality, sebuah industri yang bergerak di bidang pelayanan jasa sosial semakin berkembang pesat di Indonesia, khususnya di Yogyakarta. Industri ini bergerak dalam hal jasa perhotelan dan pengelolaan acara sosial keagamaan, seperti pernikahan. Berdasarkan data yang diperoleh, masyarakat Yogyakarta amat sensitif terhadap jaminan produk yang berkualitas.

Sikap konsumen terhadap keputusan konsumsi sebuah produk, biasanya didasari oleh pandangan dan proses pembelajaran atas produk tersebut. Proses belajar, bisa merupakan pengalaman pribadi maupun informasi pengalaman orang lain. Sikap konsumen seringkali mempengaruhi penilaiannya terhadap suatu produk, oleh karenanya bisa positif maupun negatif. Konsumen dalam menilai suatu produk, dipengaruhi oleh keadaan jiwa dan pola pikirnya, dimana keadaan jiwa tersebut dipengaruhi oleh tradisi, keyakinan, kebiasaan dan budaya masyarakatnya. Sedangkan kegunaan bauran pemasaran sebagai kerangka acuan dalam 
rangka memberikan kecocokan antara berbagai macam unsur yang harus dipertimbangkan saat menentukan strategi pemasaran perusahaan.

Tingginya permintaan akan jasa di bidang hospitality di Yogyakarta, mendorong makin banyaknya jasa sejenis yang bermunculan di kota ini. Hal ini tentu saja menimbulkan meningkatnya suhu persaingan. Kunci sukses sebuah bisnis adalah bagaimana dia mampu memenangkan konsumen, yang diawali dengan membangun sikap positif sehingga mampu mendorong konsumen untuk melakukan keputusan pembelian.

Berdasarkan uraian tersebut, maka permasalahan pada penelitian ini adalah bagaimana sikap konsumen terhadap bauran pemasaran hospitality di Yogyakarta?

\section{KAJIAN TEORI}

\section{Definisi Sikap}

Sikap menurut L.L. Thurstone dalam Engel (1994:106), adalah afeksi atau perasaan individu terhadap sebuah rangsangan. Biasanya individu yang menerima suatu ransangan akan memberikan respon terhadap rangsangan tersebut. Respon yang diberikan setiap individu tidaklah sama, tergantung pada sifat, karakter, keyakinan dan nilai-nilai dasar yang dianut dalam kehidupannya. Sikap terbentuk dan tersimpan dalam memori jangka panjang setiap individu, yang dapat diingat kembali pada saat yang tepat untuk membantunya menghadapi sebuah isu atau masalah. Dari sudut pandang manajemen pemasaran, sikap memiliki 4 fungsi yaitu (Daniel Katz dalam Sunarto, 2003:160):

a. Fungsi Utilitarian

Fungsi ini mengacu pada ide bahwa individu mengekspresikan perasaaan untuk memaksimalkan penghargaan dan meminimalkan hukuman yang mereka terima dari orang lain. Sikap akan memandu perilaku untuk mendapatkan penguatan positif dan menghindari hukuman.

b. Fungsi Pembelaan Ego (Ego-Defensive)

Fungsi pembelaan ego, melindungi orang dari kebenaran mendasar tentang diri sendiri atau dari kenyataan yang kurang baik dari pihak luar. Ego defensive juga sering disebut dengan fungsi pertahanan diri dari individu untuk mempertahan harga diri. Jadi fungsi sikap disini merupakan mekanisme pembelaan individu yang fanatik terhadap apa yang diyakininya.

c. Fungsi Pengetahuan (Knowledge Function)

Sikap juga dapat digunakan sebagai standar yang membantu seseorang untuk memahami dunia mereka, dengan fungsi pengetahuan sikap individu membentuk sebuah kerangka kerja referensi yang mana mereka mengitepretasikan dunianya. Dalam ini sikap konsumen sangat dipengaruhi bagaimana mereka secara selektif mengekspos dirinya dan mengamati komunikasi pemasaran.

d. Fungsi Nilai-Ekspresif

Fungsi ini mengacu pada bagaimana seseorang mengekspresikan nilai sentral mereka kepada orang lain. Fungsi ini dapat dilihat pada situasi dimana individu mengekpresikan pandangan positif tentang berbagai produk, merek dan jasa dalam rangka membuat pernyataan tentang diri mereka. 


\section{Komponen Norma Subyektif}

Komponen ini bersifat eksternal individu yang mempunyai pengaruh terhadap perilaku individu. Komponen normatif ini dapat dihitung dengan mengalikan antara nilai kepercayaan normatif individu terhadap atribut dengan motivasi terhadap atribut tersebut. Komponen ini dapat diartikan seberapa kuatnya keyakinan normatif seseorang terhadap atribut yang ditawarkan dalam mempengaruhi perilakunya terhadap obyek.

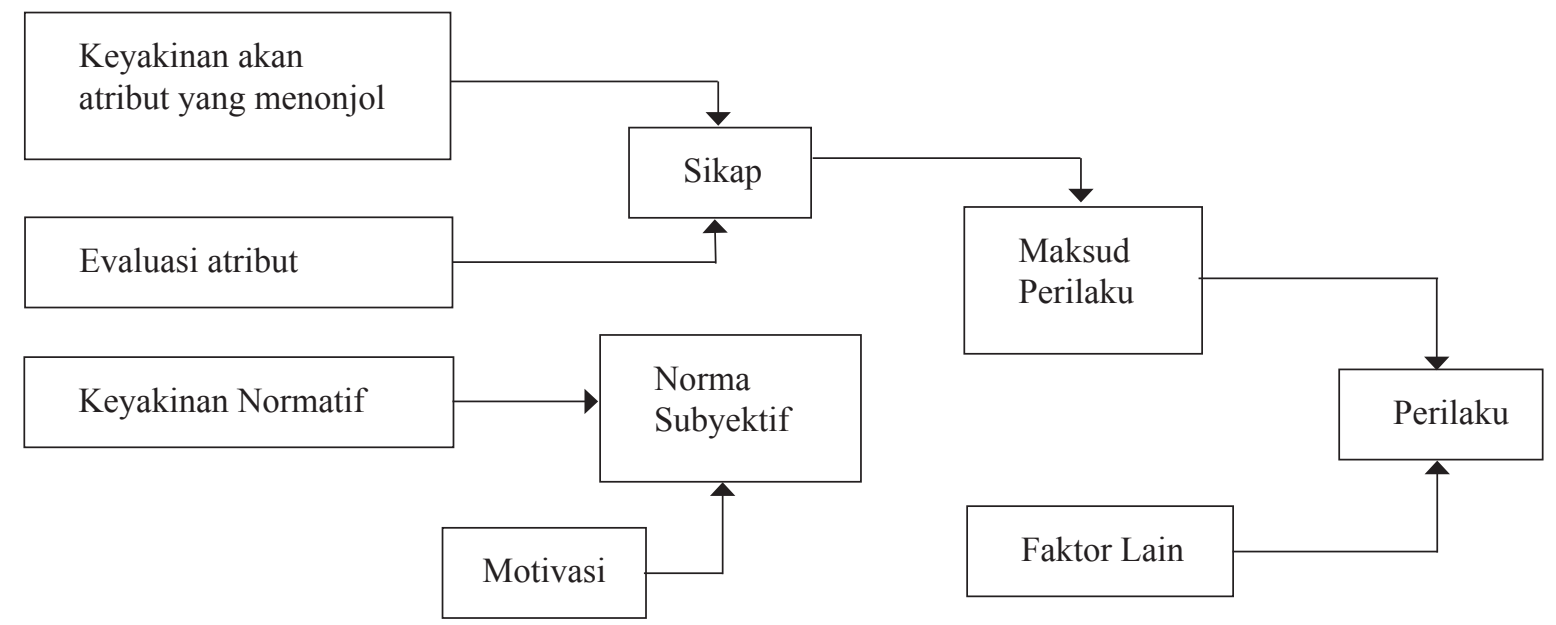

Sumber: Umar, 2010

Gambar 1

Hubungan antar Komponen dalam Model Perilaku dan Sikap Fishbein

Sifat yang penting dari sikap adalah kepercayaan dalam memegang sikap tersebut. Beberapa sikap mungkin dipegang dengan keyakinan kuat, sementara yang lain ada dengan tingkat kepercayaan yang minim. Tingkat kepercayaan yang dihubungkan dengan sikap merupakan faktor penting karena dapat mempengaruhi kekuatan hubungan diantara sikap dan perilaku. Selain itu kepercayaan dapat mempengaruhi kerentanan sikap terhadap perubahan. Sikap akan menjadi lebih resistan terhadap perubahan bila dipegang dengan kepercayaan yang lebih besar (Engel dkk, 2012). Sikap yang terbentuk sebagai hasil dari kontak langsung dengan obyek biasanya mengikat kepercayaan yang lebih besar daripada sikap yang terbentuk tanpa pengalaman langsung dengan obyek.

Formasi sikap konsumen pada situasi keterlibatan tinggi dapat diuraikan dengan cara terbaik oleh model multiatribut. Model ini mengidentifikasikan bagaimana konsumen mengkombinasikan kepercayaan mereka tentang atribut produk untuk membentuk sikap terhadap berbagai alternatif merek, korporasi atau obyek lainnya. Sedangkan untuk meprediksikan sikap konsumen dapat dianalisa melalui rumus aljabar berikut ini :

$$
\text { Ao }=\sum_{i=1}^{a} \text { bi.ei }
$$

dimana :

Ao $=$ Sikap terhadap obyek

bi = Kekuatan kepercayaan bahwa obyek memiliki atribut $\mathrm{i}$

ei $=$ Evaluasi mengenai atribut $\mathrm{i}$

$\mathrm{n} \quad=$ Jumlah atribut yang menonjol 
Unsur-unsur Bauran Pemasaran

Bauran pemasaran jasa hospitality adalah sebagai berikut:

a. Produk

Produk pada bisnis hospitality meliputi dukungan layanan dan jaminan atas produk yang sesuai harapan. Dalam hal ini penting untuk diketahui bahwa tidak semua pelanggan sama. Permintaan pelanggan untuk berbagai konfigurasi manfaat, sifat-sifat dan atribut-atribut akan beragam menurut segmen pasar.

b. Harga

Harga yang dikenakan pada suatu produk/jasa memberikan sinyal mengenai jasa tersebut kepada pelanggan yang akan menerimanya. Pertimbangan dalam menetapkan harga dalam produk hospitality, diharapkan juga berdasarkan pada prinsip-prinsip pemasaran. Keputusan penetapan harga harus konsisten dengan strategi pemasaran secara keseluruhan. Penetapan harga yang digunakan seharusnya diawali dengan pertimbangan mengenai tujuan penetapan harga yang sesuai dengan tujuan penciptaan produk. Tujuan yang dimaksud adalah:

Kelangsungan hidup, keuntungan, perluasan pasar, dan ekslusivitas.

c. Lokasi

Keputusan lokasi dari saluran pemasaran meliputi pertimbangan mengenai cara menyampaikan produk kepada pelanggan dan dimana harus ditempatkan.

d. Promosi

Promosi menambah signifikansi produk dan juga dapat membantu pelanggan membuat penilaian tawaran produk dengan lebih baik. Promosi dalam memasarkan produk hospitality. Promosi yang seharusnya dilakukan dalam bisnis ini meliputi, iklan, personal selling, promosi penjualan, dan hubungan baik dengan konsumen.

\section{Definisi Pemasaran dan Bisnis Hospitality}

Menurut Kotler (2010), Manajemen pemasaran adalah seni dan ilmu memilih pangsa pasar sasaran dan mendapatkan, mempertahankan (keeping), serta menumbuhkan pelanggan melalui penciptaan, penyerahan untuk selanjutnya mengkomunikasikan nilai pelanggan yang unggul". Sedangkan Pemasaran adalah suatu proses sosial yang didalamnya individu dan kelompok mendapatkan apa yang mereka butuhkan dan inginkan dengan menciptakan, menawarkan serta secara bebas mempertukarkan produk yang bernilai dengan pihak lain". Banyak definisi yang mendeskripsikan mengenai pemasaran selama ini, salah satunya yaitu, definisi menurut American Corporate: Pemasaran adalah proses perencanaan dan pelaksanaan pikiran (conception), penetapan harga, promosi, dan penyaluran gagasan, barang, serta jasa untuk menciptakan pertukaran yang memenuhi kepuasaan tujuan (goals) individual dan organisasional. Sedang bisnis hospitality, yaitu bisnis yang bergerak dalam bidang jasa. Jasa yang dimaksud adalah, perhotelan, rumah makan, penyewaan gedung pertemuan, dan pengelolaan upacara pernikahan. 


\section{METODE PENELITIAN}

Penelitian ini merupakan penelitian kuantitatif dengan metode sampling. Sampel diambil dari populasi subyek penelitian yang ada. Sumber data yang digunakan dalam penelitian ini adalah data primer yang merupakan data yang diambil langsung dari lapangan dan data sekunder yang sifatnya sebagai pelengkap. Penelitian ini menggunakan pendekatan deskriptif-evaluatif. Menurut Arikunto dalam Umar Husein (2010:273) penelitian deskriptif tidak dimaksudkan untuk menguji hipotesis tertentu, tetapi hanya menggambarkan apa adanya tentang suatu variabel, gejala atau fenomena. Sedangkan pendekatan evaluatif merupakan suatu proses yang dilakukan dalam rangka menentukan kebijakan dengan teknik mengembangkan kerangka berpikir dalam rangka mengambil keputusan. Hasil penelitian ini diharapkan dapat memberi masukan bagi para pengambil keputusan di bidang bisnis hospitality, khususnya di Yogyakarta.

Subyek penelitian dalam penelitian ini adalah konsumen dan konsumen potensial produk hospitality. Pengambilan sampel menggunakan kombinasi stratified sampel dan sampel random. Sampel random digunakan untuk menentukan perusahaan mana sajakah yang akan dijadikan sebagai sampel dalam penelitian ini. Dari teknik maka akan ditentukan sejumlah " $n$ " sampel dari keseluruhan perusahaan yang bergerak di bidang hospitality di Yogyakarta. Setelah ditentukan jumlah "n" sampelnya, maka data akan ditentukan secara acak (random), sehingga semua konsumen produk hospitality yang dijadikan subyek penelitian mempunyai tingkat probabilitas yang sama untuk dijadikan sampel guna menentukan besarnya 'rs', dengan menggunakan rumus sebagai berikut:

$$
\mathrm{rs}=1-\frac{6 \sum_{\mathrm{I}=1}^{\mathrm{N}} \mathrm{di}^{2}}{\mathrm{~N} 3-\mathrm{N}}
$$

Teknik pengambilan data dilakukan melalui kuesioner, wawancara dan dokumentasi. Selanjutnya data dianalisis menggunakan software SPSS 15 for Windows.

Penelitian dilakukan di Daerah Istimewa Yogyakarta, selama kurun waktu 3 bulan, yang dimulai bulan April sampai dengan Juli 2015.

\section{HASIL DAN PEMBAHASAN}

Penelitian mengenai sikap konsumen terhadap bauran pemasaran hospitality di Yogyakarta ini bertujuan untuk mengetahui sikap konsumen terhadap produk-produk yang ditawarkan pada bisnis di bidang hospitality di Yogyakarta.

\section{Uji Instrumen}

Hasil Uji validitas dan reliabilitas kuesioner yang diberikan kepada sejumlah 120 responden, yang merupakan sampel penelitian dilakukan dengan menggunakan SPSS 15 for Windows. Hasil uji validitas dan reliabilitas dapat dilihat sebagai berikut:

a. Hasil uji validitas kuesioner pada instrumen faktor-faktor yang mempengaruhi penggunaan produk hospitality di Yogyakarta dapat dilihat pada rangkuman tabel berikut: 
Tabel 1

Rangkuman Analisis Validitas

\begin{tabular}{ccccc}
\hline No & Rxy & Rbt & P & status \\
\hline $\mathbf{1}$ & 0.771 & 0,505 & 0,002 & Valid \\
$\mathbf{2}$ & 0,714 & 0,539 & 0,001 & Valid \\
$\mathbf{3}$ & 0,791 & 0,509 & 0,002 & Valid \\
$\mathbf{4}$ & 0,687 & 0,526 & 0,002 & Valid \\
\hline
\end{tabular}

Berdasarkan tabel 1 dapat diketahui bahwa pada taraf signifikansi 0,05, koefisien rxy antara 0,687 sampai dengan 0,791 dan rbt antara 0,505 sampai dengan 0,539 dimana $p<0,05$, hal ini menunjukkan bahwa seluruh butir kuesioner tersebut valid. Sedang berdasarkan hasil uji reliabilitas dapat diketahui bahwa pada taraf signifikansi 0,05 diperoleh $\mathrm{rtt} 0,706, \mathrm{p}<0,05$, artinya bahwa butir kuesioner pada instrumen faktor-faktor yang mempengaruhi penggunaan hospitality di Yogyakarta adalah handal. Secara lebih rinci rangkuman hasil uji analisis dapat dilihat pada tabel rangkuman analisis berikut ini:

Tabel 2

Rangkuman Analisis

\begin{tabular}{lll}
\hline No & Keterangan / Simbul & \multicolumn{1}{c}{ Nilai } \\
\hline 1 & Jumlah Butir Sahih : MS & 4 \\
2 & Jumlah Kasus Semula : N & 30 \\
3 & Jumlah Data Hilang : NG & 0 \\
4 & Jumlah Kasus Jalan : NJ & 30 \\
5 & Sigma X : $\Sigma \mathrm{X}$ & 253 \\
6 & Sigma X Kuadrat $: \Sigma \mathrm{X}_{2}$ & 2345 \\
7 & Variansi X : $\alpha_{2} \mathrm{X}$ & 4 \\
8 & Variansi Y : $\alpha_{2} \mathrm{Y}$ & 8 \\
9 & Koef Alpha : rtt & 0,706 \\
10 & Peluang Galat $\alpha:$ & 0,000 \\
11 & Status & Handal \\
\hline
\end{tabular}

Sumber : Hasil Analisis

b. Hasil uji validitas kuesioner pada variabel keyakinan (bi) konsumen hospitality di Yogyakarta terhadap bauran pemasaran produk hospitality dapat dilihat pada tabel 3 berikut: 
Tabel 3

Hasil Validitas Variabel Keyakinan

\begin{tabular}{ccccc}
\hline No & Rxy & Rbt & P & Status \\
\hline 1 & 0,503 & 0,440 & 0,007 & Valid \\
2 & 0,610 & 0,552 & 0,001 & Valid \\
3 & 0,558 & 0,463 & 0,005 & Valid \\
4 & 0,784 & 0,725 & 0,000 & Valid \\
5 & 0,537 & 0,401 & 0,013 & Valid \\
6 & 0,669 & 0,593 & 0,000 & Valid \\
7 & 0,469 & 0.374 & 0,020 & Valid \\
8 & 0,612 & 0,535 & 0,001 & Valid \\
9 & 0,636 & 0,558 & 0,001 & Valid \\
10 & 0,559 & 0,487 & 0,003 & Valid \\
11 & 0,615 & 0,552 & 0,001 & Valid \\
12 & 0,667 & 0,596 & 0,000 & Valid \\
13 & 0,832 & 0,078 & 0,000 & Valid \\
14 & 0,698 & 0,629 & 0,000 & Valid \\
\hline Sumber : Data penelitian & & &
\end{tabular}

Berdasarkan tabel 3 dapat diketahui bahwa pada taraf signifikansi 0,05, koefisien rxy antara 0,469 sampai dengan 0,832 dan rbt antara 0,374 sampai dengan 0,725 dimana $\mathrm{p}<0,05$, hal ini menunjukkan bahwa seluruh butir kuesioner tersebut valid. Sedang berdasarkan hasil uji reliabilitas dapat diketahui bahwa pada taraf signifikansi 0,05 diperoleh $\mathrm{rtt} 0,875, \mathrm{p}<0,05$, artinya bahwa butir kuesioner pada instrumen faktor-faktor yang mempengaruhi penggunaan produk hospitality di Yogyakarta adalah handal. Secara lebih rinci rangkuman hasil uji analisis dapat dilihat pada tabel rangkuman analisis berikut ini:

Tabel 4

Rangkuman Analisis

\begin{tabular}{lll}
\hline No & \multicolumn{1}{c}{ Keterangan/Simbul } & \multicolumn{1}{c}{ Nilai } \\
\hline 1 & Jumlah Butir Sahih : MS & 14 \\
2 & Jumlah Kasus Semula : N & 30 \\
3 & Jumlah Data Hilang : NG & 0 \\
4 & Jumlah Kasus Jalan : NJ & 30 \\
5 & Sigma X : $\Sigma$ X & 341 \\
6 & Sigma X Kuadrat : $\Sigma \mathrm{X}_{2}$ & 5119 \\
7 & Variansi X : $\alpha 2 \mathrm{X}$ & 8 \\
8 & Variansi Y : $\alpha 2 \mathrm{Y}$ & 41 \\
9 & Koef Alpha : rtt & 0,875 \\
10 & Peluang Galat $\alpha:$ & 0,000 \\
11 & Status & Handal \\
\hline
\end{tabular}

Sumber : Hasil Analisis 
c. Hasil uji validitas kuesioner pada variabel evaluasi (ei) konsumen terhadap bauran pemasaran produk hospitality di Yogyakarta, dapat dilihat pada tabel 3 berikut:

Tabel 5

Hasil Uji Validitas Variabel Evaluasi

\begin{tabular}{lllll}
\hline No & Rxy & Rbt & P & Status \\
\hline 1 & 0,680 & 0,639 & 0,000 & Valid \\
2 & 0,604 & 0,524 & 0,002 & Valid \\
3 & 0,532 & 0,415 & 0,011 & Valid \\
4 & 0,815 & 0,766 & 0,000 & Valid \\
5 & 0,511 & 0,373 & 0,020 & Valid \\
6 & 0,469 & 0,380 & 0,018 & Valid \\
7 & 0,476 & 0.401 & 0,013 & Valid \\
8 & 0,501 & 0,427 & 0,009 & Valid \\
9 & 0,733 & 0,678 & 0,000 & Valid \\
10 & 0,752 & 0,696 & 0,000 & Valid \\
11 & 0,768 & 0,728 & 0,000 & Valid \\
12 & 0,627 & 0,540 & 0,001 & Valid \\
13 & 0,718 & 0,651 & 0,000 & Valid \\
14 & 0,721 & 0,657 & 0,000 & Valid \\
\hline
\end{tabular}

Sumber: Data penelitian

Berdasarkan tabel 3 dapat diketahui bahwa pada taraf signifikansi 0,05, koefisien rxy antara 0,469 sampai dengan 0,815 dan rbt antara 0,373 sampai dengan 0,766 dimana $p<0,05$, hal ini menunjukkan bahwa seluruh butir kuesioner tersebut valid. Sedang berdasarkan hasil uji reliabilitas dapat diketahui bahwa pada taraf signifikansi 0,05 diperoleh rbt 0,877, p < 0, 05, artinya bahwa butir kuesioner pada instrumen faktor-faktor yang mempengaruhi penggunaan produk hospitality di Yogyakarta adalah handal. Secara lebih rinci rangkuman hasil uji analisis dapat dilihat pada tabel rangkuman analisis berikut ini:

Tabel 6

Rangkuman Analisis

\begin{tabular}{lll}
\hline No & Keterangan / Simbul & Nilai \\
\hline 1 & Jumlah Butir Sahih : MS & 14 \\
2 & Jumlah Kasus Semula : N & 30 \\
3 & Jumlah Data Hilang : NG & 0 \\
4 & Jumlah Kasus Jalan : NJ & 30 \\
5 & Sigma X : $\Sigma$ X & 368 \\
6 & Sigma X Kuadrat : $\Sigma$ X 2 & 5580 \\
7 & Variansi X : $\alpha 2$ X & 7 \\
8 & Variansi Y : $\alpha 2$ Y & 36 \\
9 & Koef Alpha : rtt & 0,877 \\
10 & Peluang Galat $\alpha:$ & 0,000 \\
11 & Status & Handal \\
\hline Sumber: Hasil Analisis &
\end{tabular}

Sumber: Hasil Analisis 


\section{Hasil Analisis Faktor-faktor yang mempengaruhi Penggunaan produk hospitality di Yogyakarta}

Faktor-faktor yang mempengaruhi penggunaan produk hospitality di Yogyakarta diidentifikasi melalui: alasan, sumber informasi, pemberi saran dan pengambil keputusan untuk menggunakan produk hospitality di Yogyakarta. Adapun hasilnya sebagai berikut:

\section{Alasan Menggunakan}

Tabel 7

Alasan yang Mendorong Konsumen untuk Menggunakan Produk Hospitality

\begin{tabular}{lcc}
\hline Alasan & Frekuensi & Persentase \\
\hline Layanan produk & 60 & $60 \%$ \\
Biaya yang konsisten & 28 & $28 \%$ \\
Promosi yang menarik & 4 & $4 \%$ \\
Lokasi yang mudah & 7 & $7 \%$ \\
Lain -lain & 1 & $1 \%$ \\
Total & 100 & $100 \%$ \\
\hline Sumber data penelitian diolah & &
\end{tabular}

Sumber : data penelitian diolah

Berdasarkan tabel 7 dapat dilihat bahwa faktor utama yang menjadi alasan konsumen untuk menggunakan produk hospitality di Yogyakarta adalah karena layanan yaitu sebesar 60\%. Selanjutnya diikuti oleh biaya, promosi yang santun, lokasi yang mudah dijangkau dan alasan lainnya.

\section{Sumber Informasi}

Tabel 8

Sumber Informasi Mengenai Produk Hospitality

\begin{tabular}{lcc}
\hline Sumber Informasi & Frekuensi & Persentase \\
\hline Promosi yang menarik & 25 & $25 \%$ \\
Lingkungan Keluarga & 10 & $10 \%$ \\
Relasi/teman & 62 & $62 \%$ \\
Kantor tempat mereka bekerja & 2 & $2 \%$ \\
Lain -lain & 1 & $1 \%$ \\
Total & 100 & $100 \%$ \\
\hline
\end{tabular}

Sumber : data penelitian diolah

Berdasarkan tabel 8 dapat dilihat bahwa faktor utama yang menjadi sumber informasi konsumen untuk menggunakan produk hospitality di Yogyakarta adalah berasal dari informasi teman/relasi yaitu sebesar $62 \%$. Selanjutnya diikuti oleh promosi, lingkungan keluarga, kantor dimana mereka bekerja \& alasan lainnya. 


\section{Pemberi Saran}

Tabel 9

Pemberi Saran untuk Menggunakan Produk Hospitality di Yogyakarta

\begin{tabular}{lcc}
\hline Pemberi Saran & Frekuensi & Persentase \\
\hline Keluarga & 31 & $31 \%$ \\
Relasi/teman & 37 & $37 \%$ \\
Kantor & - & - \\
Lain-lain & 32 & $32 \%$ \\
Total & 100 & $100 \%$ \\
\hline
\end{tabular}

Sumber: Data penelitian diolah

Berdasarkan tabel 9 dapat dilihat bahwa faktor utama yang memberi saran konsumen untuk menggunakan produk hospitality di Yogyakarta adalah berasal dari informasi teman/ relasi yaitu sebesar 37\%. Selanjutnya diikuti saran dari berbagai sumber (lain-lain) \& keluarga.

\section{Pihak yang Mengambil Keputusan}

Tabel 10

Pihak yang Berperan dalam Mengambil Keputusan

\begin{tabular}{llr}
\hline $\begin{array}{c}\text { Pihak yang berperan dalam } \\
\text { mengambil keputusan }\end{array}$ & Frekuensi & Persentase \\
\hline Diri sendiri & 85 & $85 \%$ \\
Keluarga & 9 & $9 \%$ \\
Teman/relasi & 5 & $5 \%$ \\
Lain-lain & 1 & $1 \%$ \\
Total & 100 & $100 \%$ \\
\hline Sumber : data penelitian diolah & &
\end{tabular}

Berdasarkan tabel 10 dapat dilihat bahwa faktor utama yang berperan dalam mengambil keputusan konsumen untuk menggunakan produk hospitality di Yogyakarta adalah diri sendiri yaitu sebesar $85 \%$. Selanjutnya diikuti keluarga, teman/relasi dan lain-lain.

Keyakinan konsumen terhadap suatu produk merupakan hal yang penting bagi setiap usaha, termasuk usaha di bidang hospitality. Keyakian konsumen terhadap produk hospitality merupakan pengetahuan yang dimiliki konsumen atas suatu produk maupun jasa beserta kesimpulan tentang bauran pemasaran produk hospitality. Berdasarkan penelitian yang telah dilakukan, secara menyeluruh dapatlah diketahui bahwa para konsumen merasa yakin terhadap kualitas produk yang berkualitas dengan layanan produk yang diwujudkan dalam bentuk layanan yang ramah yang didapatkan ketika membeli produk tersebut. Para konsumen juga merasa yakin bahwa harga yang ditawarkan senantiasa konsisten antara kenyataan dengan yang ditawarkan melalui promosi, bahkan para konsumen meyakini adanya kejujuran dalam penetapan harganya sehingga harga dirasa tidak mahal.

Berdasarkan hasil penelitian yang dilakukan dengan mengunakan teknik formulasi Fishbein, yaitu suatu formulasi yang mengemukakan bahwa sikap terhadap obyek didasarkan pada perangkat kepercayaan dan diberi bobot evaluasi terhadap atribut (Engel dkk, 2010), maka 
dapat diketahui bahwa nilai sikap konsumen terhadap bauran pemasaran produk hospitality di Yogyakarta adalah sangat baik. Rentang nilai sikap maksimum konsumen terhadap bauran pemasaran produk hospitality di Yogyakarta adalah $+12,13$ (sangat baik) dan nilai minimum adalah - 12,13 (sangat tidak baik). Adapun secara rinci nilai rentang sikap yang dimaksud adalah sebagai berikut :

Tabel 11

Rentang Nilai Sikap Konsumen terhadap Bauran Pemasaran Produk Hospitality di Yogyakarta

\begin{tabular}{lll}
\hline Skor & Nilai Sikap & Kriteria \\
\hline+2 & $6,066 \mathrm{~s} / \mathrm{d}$ 12,13 & Sangat baik \\
+1 & $0,001 \mathrm{~s} / \mathrm{d}$ 6,065 & Baik \\
0 & 0 & Netral \\
-1 & $-6,065 \mathrm{~s} / \mathrm{d}-0,001$ & Tidak baik \\
-2 & $-12,13 \mathrm{~s} / \mathrm{d}-6,066$ & Sangat tidak baik \\
\hline Sumber : data penelitian diolah &
\end{tabular}

Berdasarkan tabel 11, dapat diketahui bahwa rentang nilai sikap konsumen terhadap bauran pemasaran produk hospitality di Yogyakarta termasuk dalam kategori baik yaitu + 5,1601 . Hal ini menunjukkan bahwa penerapan bauran pemasaran yang telah dilakukan oleh produk hospitality di Yogyakarta mendapat sikap yang positif dan baik dimata konsumennya.

\section{SIMPULAN DAN SARAN}

Dari hasil analisis yang telah diuraikan sebelumnya, maka dapat diambil kesimpulan sebagai berikut:

1. Sikap konsumen secara keseluruhan terhadap bauran pemasaran produk hospitality di Yogyakarta yang terdiri atas: produk, harga, promosi, partisipan, proses dan layanan pelanggan adalah positif signifikan dengan nilai $\mathrm{Ao}=+5.1601$.

2. Secara parsial sikap konsumen terhadap produk hospitality di Yogyakarta adalah positif signifikan dengan nilai Ao $=+1.047025$

3. Secara parsial sikap konsumen terhadap harga produk hospitality di Yogyakarta adalah positif signifikan dengan nilai Ao $=+0.58305$

4. Secara parsial sikap konsumen terhadap lokasi produk hospitality di Yogyakarta adalah positif signifikan dengan nilai $\mathrm{Ao}=+0.980075$

5. Secara parsial sikap konsumen terhadap promosi poduk hospitality di Yogyakarta adalah positif signifikan dengan nilai Ao $=+0.3479$

6. Secara parsial sikap konsumen terhadap partisipan produk hospitality di Yogyakarta adalah positif signifikan dengan nilai Ao $=+7395$

7. Secara parsial sikap konsumen terhadap proses penyediaan produk hospitality di Yogyakarta adalah positif signifikan dengan nilai $\mathrm{Ao}=+1.055$

8. Secara parsial sikap konsumen terhadap layanan pelanggan produk hospitality di Yogyakarta adalah positif signifikan dengan nilai $\mathrm{Ao}=+0.40755$ 
Berdasarkan kesimpulan yang dapat diambil, maka dapat diberikan saran sebagai berikut:

1. Para pengusaha yang mengelola usaha hospitality di Yogyakarta hendaknya selalu menjaga kualitas layanan agar tidak ditinggalkan pelanggan.

2. Mengingat masih terdapat pelanggan yang potensial, yang ditandai dengan jawaban netral terhadap pertanyaan yang diberikan, maka para pengusaha yang bergerak di bidang ini diharapkan lebih meningkatkan kualitas layanannya, terutama dari sisi jaminan layanan yang ramah. Hal ini perlu dilakukan, karena tujuan bisnis tidaklah semata-mata mengejar keuntungan finansial, namun juga mencari keberlangsungan jangka panjang.

\section{REFERENSI}

Algifari. 1997. Statistika Induktif untuk Ekonomi dan Bisnis. Yogyakarta: UPP AMP YKPN.

Aviliani dan Wilfredus. 1997. Membangun Kepuasan Pelanggan melalui Kualitas Pelayanan. Jakarta: Majalah Usahawan No. 5.

Barelson, Bernard and Gerry Stainer. 1994. Human Behaviour an Inventory of Scientifics Findings. New York: Harcort Brace Jovanovich.

Beng, Soo Ong. 2015. Attitudes Perceptions And Responses Of Purchasers Versus SubscribesOnly For Daily Deals On Hospitality Products. Journal of Hospitality Marketing and Management. Vol. 24-Issue 2:180-201.

Groonroos, Cristian. 2006. Service Management and Marketing (Managing the Moments of Truth in Service Competition) New York: Maxwell Mc. Millan Int.

Engel. 1994. Perilaku Konsumen. Jakarta: Binarupa Akasara.

Kotler, Philip. 2010. Marketing Management New Edition: Analysis, Planning, Implementation and Control, 9 th Ed. Englewood Clifts. NJ: Prentice-Hall International, Inc.

Leichty, M and Gilbert Churchill Jr. 2009. Conceptual Insigts Into Consumer Satisfaction With. Chicago: ECP.

Leung, Xi Y. 2015. The Marketing Effectiveness of Social Media in The Hotel Industry, Journal of Hospitality \& Tourism Research. Vol. 39. No. 2:147-169.

Naresh K., Maholtra. 1996. Marketing Research: An applied Orientation. Second Edition. Prentice Hall International, Inc.

Sunarto. 2003. Perilaku Konsumen. Yogyakarta: AMUS.

Swastha, Basu dan T. Hani Handoko. 2008. Manajemen Pemasaran. Yogyakarta: BPFE.

Tilikidou, Irene, Antonia Delistavrou and Nicholas Sapountzis. 2014. Customers' Ethical Behaviour Towards Hotels. Elsevier Procedia Economis and Finance. Vol. 9: 425432.

Tjiptono, Fandy. 2010. Manajemen Jasa. Yogyakarta: Penerbit Andi.

Umar, Husein. 2010. Metodologi Penelitian Aplikasi dalam Pemasaran. Jakarta: PT Gramedia Utama. 